\title{
Study on management of pediatric migraine by general practitioners in northern France
}

\author{
Jean-Christophe Cuvellier $\cdot$ Sandra Carvalho $\cdot$ \\ Amaury Mars · Stéphane Auvin
}

Received: 15 December 2008/ Accepted: 21 February 2009/Published online: 20 March 2009

(C) Springer-Verlag 2009

\begin{abstract}
The study explored the awareness of the Haute Autorité de Santé (High Health Authority, HAS) guidelines for migraine management in children among a random sample of 100 general practitioners (GPs) dichotomised in an urban and a rural group. A questionnaire conducted by phone included questions on knowledge of pediatric migraine acute treatment and preventive therapy, referral to a child neurologist as well as GPs awareness of HAS recommendations in general. Although $45 \%$ of GPs argued they were prescribing ibuprofen as first-line abortive drug, only $3 \%$ were aware of the recommended dose. Only $48 \%$ of GPs were agreeing to initiate preventive therapy. Fifty percent of GPs stated that they knew HAS guidelines but only $24 \%$ stated that they had read them. The only significant difference between urban and rural GPs concerned the initiation of preventive therapy. Continuing educational programmes on the implementation of pediatric migraine guidelines is strongly needed.
\end{abstract}

Keywords General practice - Guidelines · Migraine · Children

Electronic supplementary material The online version of this article (doi:10.1007/s10194-009-0111-9) contains supplementary material, which is available to authorized users.

J.-C. Cuvellier $(\bowtie) \cdot$ S. Carvalho · A. Mars

Division of Pediatric Neurology, Department of Pediatrics,

Lille Faculty of Medicine and Children's Hospital, rue du Pr Emile Laine, Lille, France

e-mail: jc-cuvellier@chru-lille.fr

\section{S. Auvin}

Service de Neurologie Pédiatrique et des Maladies

Métaboliques, Hôpital Robert Debré, APHP,

48 Boulevard Sérurier, 75935 Paris Cedex 19, France

\section{Introduction}

The estimated prevalence of migraine in the adolescent population ranges from $8 \%$ to $28 \%$ [1-3]. Migraine in adolescents also has been associated with disability as evidenced by missed school days [1,4], and a negative impact on quality of life [5].

Despite this high prevalence, however, clinicians may not readily recognize childhood migraine [6] and treatment appears even less satisfactory. There are many drug and non-drug therapeutic approaches for both acute and preventive treatment. The French Health Agency (High Health Authority, Haute Autorité de Santé, HAS) regularly issues clinical guidelines intended to general practitioners (GPs) dealing with the diagnosis and/or the therapeutic management of various medical conditions. Clinical guidelines for the therapeutic management of migraines in adults and children were published in 2002 and sent to every GP in France [see Appendix (Supplementary material)] [7]. In a previous study designed to assess the impact of these measures and the management of children with headaches, we analyzed the pre-referral management by GPs of children referred to our Consulting Center in the Neuropediatric Department of Lille University Hospital Center, in northern France and compared it with the recommended therapeutic management of migraines in children, such as it was issued by the HAS [8]. Our study showed that, even when the GP did diagnose migraine, adequate and logical disease management did not follow and was not in accordance with HAS guidelines in the majority of cases.

The objective of the present study was to investigate GPs' knowledge of therapeutic management of migraines in children, and in particular, their awareness of HAS guidelines for migraine management in children. 


\section{Methods}

From 1 August 2007 to 31 March 2008, a survey was conducted on a random sample of 100 GPs in the northern area of France. All the GPs sampled were contacted by phone and invited to participate to the study by answering a questionnaire. They were dichotomised in two groups (50 GPs each) whether they were working in an urban or rural area. If the invited GP declined to participate to the study, the next GP on the list was contacted. The interviewed GPs were informed that the study concerned pediatric migraine but they were unaware of the precise study subject, in order to obtain the more spontaneous answers as possible.

The questionnaire included questions focusing on GPs' behavior in terms of the management of pediatric migraine in their daily practice and their knowledge of HAS recommendations. It was composed of single and multiple choice items, as well as closed questions. Questions 1-5 concerned acute treatment, questions 6-7 preventive therapy. Questions 8-10 had a larger scope and were dealing with GPs awareness of HAS recommendations. Quantitative variables were compared using the $\chi^{2}$ test. A probability level of $P<0.05$ was considered significant. Table 1 shows the 10 questions asked in questionnaire. Correlations between questions 1-4 and, respectively, questions 9 and 10 were calculated using Pearson $\chi^{2}$ test.

\section{Results}

One hundred and forty-three GPs were contacted by phone during the study period. Forty-three GPs declined to participate to the study, arguing either they were too busy ( $n=31,22 \%$ ), or they had no interest for the issue of pediatric migraine $(n=12,8 \%)$. The mean age of the sample of GPs was 42.3 years (range 35-68 years). The majority of theses GPs were men (95\%). As expected 100 GPs were included in the study, divided in an urban [ $n=50$, mean age 41.7 years (range 35-66 years), men $92 \%]$ and a rural group $[n=50$, mean age 42.9 years (range 36-68 years), men 98\%]. Table 2 shows the respondents' behavior about pediatric migraine patient management and awareness of HAS recommendations.

\section{Abortive treatment (Questions 1-5)}

\section{Acute medications}

Forty-five GPs argued they were prescribing ibuprofen as first-line abortive drug, whereas 44 GPs argued they were prescribing ibuprofen as second-line intention migraine abortive drug. The second most frequently prescribed medication was paracetamol, which was prescribed as
Table 1 Questionnaire

Question $1^{\mathrm{b}}$

What is your first intention acute medication for a migraine attack (in children and adolescents 15 or younger)?

1. Aspirin

2. Diclofenac

3. Ibuprofen

4. Niflumic acid

5. Opioids

6. Paracetamol

7. Sumatriptan

8. Other

Question $2^{\text {b }}$

What is your second intention acute medication for a migraine attack (in children and adolescents 15 or younger)?

1. Ibuprofen

2. Ergotamine

3. Opioids

4. Paracetamol

5. Sumatriptan

6. Other triptan

7. Aspirin

Question $3^{\mathrm{b}}$

When you prescribe ibuprofen for a migraine attack, which dose of ibuprofen do you prescribe?

1. $7.5-10 \mathrm{mg} / \mathrm{kg} / \mathrm{dose}$

2. Dose recommended for body weight

3. Other

Question $4^{\mathrm{b}}$

When you prescribe ibuprofen for a migraine attack, which number of ibuprofen doses do you prescribe for a single migraine attack?

1. 1-2 doses

2. $>2$ doses

Question $5^{\mathrm{a}}$

If you do not prescribe ibuprofen as first intention acute medication for a migraine attack, why?

1. Ibuprofen is not the reference medication

2. Too long onset of action

3. Adverse effects/toxicity

4. Not indicated and/or ineffective in pediatric migraine attack

5. No answer

6. Free answer

Question $6^{\mathrm{a}}$

Which criteria do you take into account to start preventive treatment?

1. Frequency of migraine attacks

2. Intensity of migraine attacks

3. Functional disability

4. Failure and/or poor tolerance of abortive drugs

5. Other

Question $7^{\mathrm{b}}$

Which type of preventive treatment do you start in first intention?

1. Pharmacological treatment 
Table 1 continued

$$
\begin{aligned}
& \text { 2. Non-pharmacological treatment } \\
& \text { 3. None }
\end{aligned}
$$

\section{Question $8^{\mathrm{a}}$}

When do you refer a pediatric migraine patient to a specialist?

1. Failure of abortive drugs of first intention migraine attacks

2. Failure of abortive drugs of second intention

3. Frequent and/or disabling migraine attacks

4. To start preventive treatment

5. As a matter of course

6. Other

Question $9^{\mathrm{b}}$

Do you think being aware of the HAS guidelines for the therapeutic management of acute treatment of pediatric attack?

1. Yes

2. No

Question $10^{\mathrm{b}}$

Did you read last HAS guidelines for the therapeutic management of acute treatment of pediatric migraine?

1. Yes

2. No

${ }^{a}$ For each question, tick appropriate numbers. Several answers possible. Code all that apply

${ }^{\mathrm{b}}$ For each question, tick appropriate number. Only one possible answer

first-line drug by 44 GPs and as second-line drug by 24 GPs. Aspirin was prescribed as first-line drug by 10 GPs and as second-line drug by 12 GPs. Eleven GPs asserted prescribing sumatriptan nasal spray as second-line drug.

\section{Target dose}

Among the 99 GPs prescribing ibuprofen (as first or secondline acute treatment), 96 targeted no particular dose. They contented themselves with either using oral solution dosage recommended for body weight or tablets. In this case, they prescribed $100 \mathrm{mg}$ per dose for those with a body weight of 20-39 kg, and $200 \mathrm{mg}$ per dose for those with a body weight of $40 \mathrm{~kg}$ or more. Three GPs targeted a dose of $10 \mathrm{mg} / \mathrm{kg}$ and $1 \mathrm{GP}$ was prescribing ibuprofen at a dose of $5 \mathrm{mg} / \mathrm{kg}$.

\section{Administration schedule}

The first-line medication was prescribed with a maximum of one to two doses for a single migraine attack by 44 GPs.

\section{Reasons for refusing to prescribe ibuprofen as first-line acute treatment}

Among the 55 GPs who did not prescribe ibuprofen as firstline acute treatment, $26(47 \%)$ did so by fear of the potential adverse events, $15(27 \%)$ had in mind that ibuprofen was not the reference medication of pediatric migraine attack, 8 (15\%) were unaccustomed to prescribe ibuprofen in pediatric migraine, $5(9 \%)$ were finding ibuprofen ineffective in pediatric migraine, and 1 (2\%) were finding that ibuprofen onset of action was too long.

Preventive treatment (Questions 6 and 7)

\section{Reasons for starting preventive treatment}

Preventive therapy for migraine was considered by 76 GPs when migraine attacks were frequent, by 55 GPs when the headache were becoming disabling and so were impeding routine activities, by 41 GPs when acute treatment was ineffective or when there were intolerable adverse effects from GPs when the treatment, and by 27 GPs because of severity of the migraine attacks.

\section{Type of preventive treatment}

Forty-eight GPs were agreeing to initiate preventive therapy. Forty GPs were prescribing pharmacological treatment (83\% of those agreeing to start preventive therapy) and 8 GPs were prescribing non-pharmacological treatment (17\% of those agreeing to start preventive therapy).

Referring the patient to a child neurologist (Question 8)

Referral to a child neurologist was considered by 17 GPs when first-line acute treatment was ineffective, by 53 GPs when second-line acute treatment was ineffective, by 56 GPs when migraine attacks were frequent and/or disabling, and by 6 GPs as a matter of course. Three GPs said that they never referred pediatric patients to a child neurologist because waiting period to obtain an appointment consultation was too long.

Awareness of HAS guidelines for the therapeutic management of pediatric migraine (Questions 9 and 10)

\section{Knowledge of the HAS guidelines for the therapeutic} management of pediatric migraine

Fifty GPs stated that they knew HAS guidelines for the therapeutic management of pediatric migraine. The percentage was higher for rural $(60 \%)$ than for urban GPs (48\%), but the difference was not significant $(P=0.31)$.

Reading HAS guidelines for the therapeutic management of pediatric migraine

Twenty-four percent of GPs stated that they had read HAS guidelines for the therapeutic management of pediatric 
Table 2 Awareness of respondents about management of pediatric migraine

\begin{tabular}{|c|c|c|c|c|}
\hline & Total & Urban & Rural & $\mathrm{OR}[\mathrm{CI}]$ \\
\hline \multicolumn{5}{|l|}{ Question 1. Medication of first intention } \\
\hline 1. Aspirin & 10 & 14 & 6 & $1.2[0.4-3.8]$ \\
\hline 2. Diclofenac & 0 & 0 & 0 & - \\
\hline 3. Ibuprofen & 45 & 36 & 54 & $0.5[0.2-1.1]$ \\
\hline 4. Niflumic acid & 1 & 2 & 0 & $0.3[0.1-8.2]$ \\
\hline 5. Opioids & 0 & 0 & 0 & - \\
\hline 6. Paracetamol & 44 & 48 & 40 & $1.3[0.6-3.1]$ \\
\hline 7. Sumatriptan & 0 & 0 & 0 & - \\
\hline 8. Other & 0 & 0 & 0 & - \\
\hline \multicolumn{5}{|l|}{ Question 2. Medication of second intention } \\
\hline 1. Ibuprofen & 44 & 46 & 42 & $1.2[0.5-2.5]$ \\
\hline 2. Ergotamine & 2 & 4 & 0 & $3.1[0.1-77]$ \\
\hline 3. Opioids & 0 & 0 & 0 & - \\
\hline 4. Paracetamol & 24 & 18 & 30 & $0.5[0.2-1.3]$ \\
\hline 5. Sumatriptan & 16 & 12 & 10 & $0.9[0.3-2.9]$ \\
\hline 6. Other triptan & 1 & 2 & 0 & $3.01[0.1-77]$ \\
\hline 7. Aspirin & 12 & 14 & 10 & $1.5[0.6-3.9]$ \\
\hline \multicolumn{5}{|l|}{ Question 3. Dose of ibuprofen } \\
\hline 1. $7.5-10 \mathrm{mg} / \mathrm{kg} / \mathrm{dose}$ & 3 & 2 & 4 & $0.5[0.08-2.7]$ \\
\hline 2. Dose recommended for body weight & 96 & 96 & 96 & $1[0.13-7.4]$ \\
\hline 3. Other & 1 & 2 & 0 & $5.2[0.2-111]$ \\
\hline \multicolumn{5}{|l|}{ Question 4. Number of ibuprofen doses } \\
\hline 1. 1-2 doses & 44 & 50 & 38 & $1.6[0.7-3.6]$ \\
\hline 2. $>2$ doses & 56 & 50 & 62 & $0.6[0.3-1.4]$ \\
\hline \multicolumn{5}{|c|}{ Question 5. Reasons of ibuprofen non prescription } \\
\hline 1. Not the reference medication & 17 & 20 & 14 & $1.8[0.6-5.4]$ \\
\hline 2. Too long onset of action & 2 & 4 & 0 & $5.2[0.2-111]$ \\
\hline 3. Adverse effects/toxicity & 26 & 26 & 26 & 1 \\
\hline 4. Not indicated/ineffective & 6 & 6 & 6 & 1 \\
\hline 5. No answer & 45 & 36 & 54 & - \\
\hline 6. Free answer & 8 & 16 & 0 & - \\
\hline \multicolumn{5}{|l|}{ Question 6. Criteria to start preventive treatment } \\
\hline 1. Frequency of migraine attacks & 76 & 64 & 88 & $0.3[0.1-0.7]^{*}$ \\
\hline 2. Intensity of migraine attacks & 27 & 28 & 26 & $1.1[0.5-2.7]$ \\
\hline 3. Functional disability & 55 & 52 & 58 & $0.8[0.4-1.8]$ \\
\hline 4. Failure/poor tolerance of abortive drugs & 41 & 36 & 46 & $0.7[0.3-1.5]$ \\
\hline 5. Other & 6 & 12 & 0 & - \\
\hline \multicolumn{5}{|c|}{ Question 7. Type of first intention preventive treatment } \\
\hline 1. Pharmacological treatment & 40 & 22 & 58 & $0.3[0.1-0.5]^{*}$ \\
\hline 2. Non-pharmacological treatment & 8 & 10 & 6 & $1.8[0.4-7.7]$ \\
\hline 3. None & 52 & 68 & 36 & $2.3[1,1-5]^{*}$ \\
\hline \multicolumn{5}{|l|}{ Question 8. Referral to a specialist } \\
\hline 1. Failure of first intention abortive drug & 17 & 14 & 20 & $7.4[0.4-147]$ \\
\hline 2. Failure of second intention abortive drug & 53 & 58 & 48 & $1.4[0.7-3.3]$ \\
\hline 3. Frequent and/or disabling attacks & 56 & 58 & 54 & $1.6[0.7-3.5]$ \\
\hline 4. Start preventive treatment & 52 & 58 & 46 & $2.1[0.3-12]$ \\
\hline 5. As a matter of course & 6 & 8 & 4 & $0.8[0.3-2.4]$ \\
\hline 6. Other & 3 & 6 & 0 & - \\
\hline
\end{tabular}


Table 2 continued

\begin{tabular}{|c|c|c|c|c|}
\hline & Total & Urban & Rural & $\mathrm{OR}[\mathrm{CI}]$ \\
\hline \multicolumn{5}{|c|}{ Question 9. Knowledge of HAS guidelines for pediatric migraine } \\
\hline 1. Yes & 54 & 48 & 60 & $0.6[0.3-1.3]$ \\
\hline 2. No & 46 & 52 & 40 & $1.6[0.7-3.5]$ \\
\hline \multicolumn{5}{|c|}{ Question 10. Reading of HAS guidelines for pediatric migraine } \\
\hline 1. Yes & 24 & 24 & 24 & $1[0.4-2.5]$ \\
\hline 2. No & 76 & 76 & 76 & $1[0.4-2.5]$ \\
\hline
\end{tabular}

$O R$ odds ratio, $C I$ confidence interval

* $P<0.05$

migraine. The percentage was identical both for rural and urban GPs. Figure analyzes knowledge of reference treatment of pediatric migraine by the GPs according to knowledge of the HAS guidelines for the therapeutic management of pediatric migraine. Figure also shows GPs prescription of ibuprofen according to their knowledge of the treatment of reference. Fifty-four GPs stated that they knew the treatment recommended for pediatric migraine. Among these GPs, 18 (33\%) stated that they had read HAS guidelines for the therapeutic management of pediatric migraine (Fig. 1). Among the 54 GPs stating being aware of the reference treatment, $33(61 \%)$ were prescribing ibuprofen as first-line acute drug for pediatric migraine (Fig. 1). Forty-six GPs stated that they did not know the reference treatment among which $5(11 \%)$ had read HAS guidelines (Fig. 1). Among these 46 GPs, 12 (26\%) were nevertheless prescribing ibuprofen as first-line acute (Fig. 1). Seventy-seven GPs stated that they never had read 2002 HAS guidelines. There was no significant correlation between the fact of answering questions 1-4 correctly and knowledge of the HAS guidelines $(P=0.243)$ or reading of the HAS guidelines $(P=0.059)$. Conversely, the correlation between stating to know HAS guidelines and stating having read them was significant $(P=0.008)$.

\section{Discussion}

Acute medications

Few well-designed trials have evaluated the acute pharmacologic management of migraine in children $[9,10]$. In 1997, the study by Hämäläinen et al. [11] was the first randomized, double-blind, placebo-controlled trial dedicated to abortive treatment of pediatric migraine. It compared acetaminophen $(15 \mathrm{mg} / \mathrm{kg})$ and ibuprofen $(10 \mathrm{mg} / \mathrm{kg})$ in a single dose three-way crossover study that showed that both drugs were well-tolerated and effective in relieving migraine attacks. Another study showed that a lower ibuprofen dosage $(7.5 \mathrm{mg} / \mathrm{kg})$ was more effective than placebo in reducing headache severity at $2 \mathrm{~h} \mathrm{[12].}$ Evers et al. [13] compared the efficacy of oral zolmitriptan,
Fig. 1 HAS guidelines and ibuprofen prescription according to knowledge of reference treatment. HAS Haute Autorité de Santé, High Health Authority

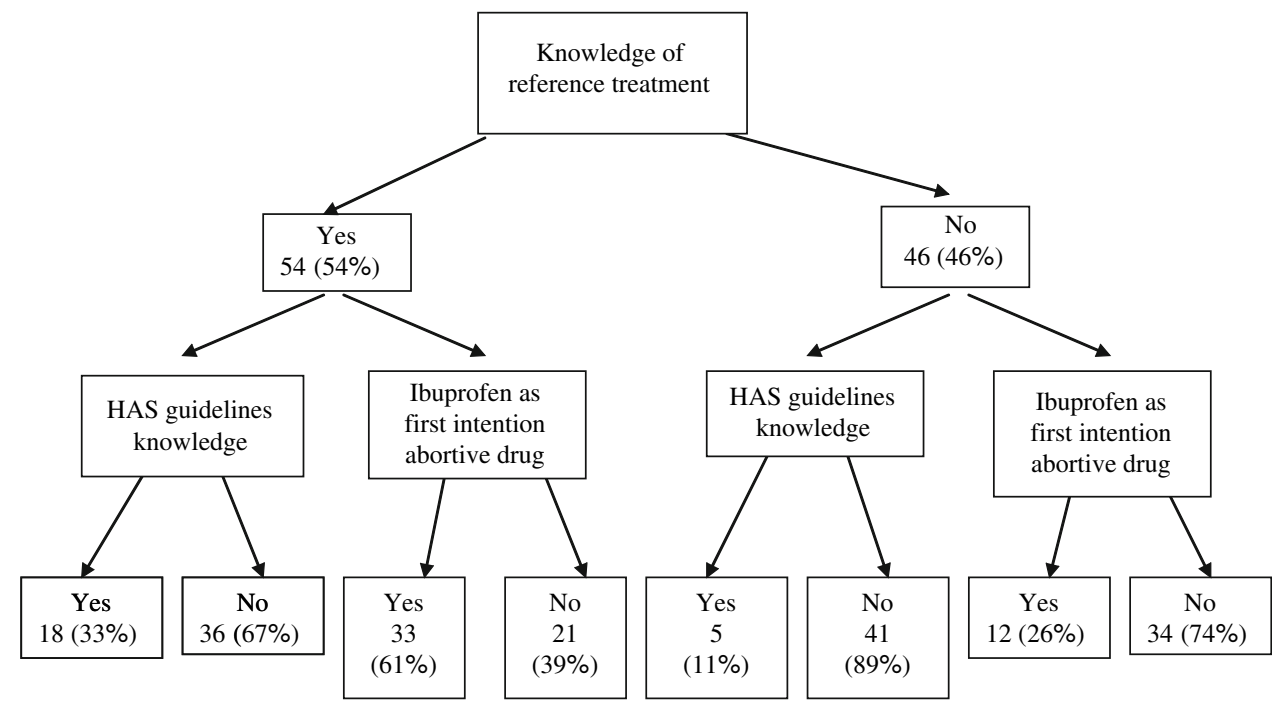


ibuprofen and placebo. They found that ibuprofen 200$400 \mathrm{mg}$ was more effective than placebo in meeting pain relief after $2 \mathrm{~h}$ [13].

The HAS guidelines for the treatment of migraine in adults and children were issued in October 2002 (see Appendix) [7]. These guidelines are currently under revision. New guidelines are expected to be issued in 2009. They were sent to each GP working in France. The HAS recommended ibuprofen as the mainstay drug for acute migraine attacks in children aged 6 months or older. It also recommended switching to ergot derivatives from the age of 10 onward and to sumatriptan nasal spray in children and adolescents 12 or older in case of inefficacy of ibuprofen. Although the HAS did not advocate the use of paracetamol in its guidelines for the treatment of migraine in adults and children, paracetamol was the drug of choice favoured by GPs. Moreover, when a little less than half of the GPs would prescribe ibuprofen as first intention drug for migraine attack, only $3 \%$ of the GPs interviewed knew the correct dosage. This figure is in line with the data of a previous survey from our hospital, where we analyzed previous headache treatment by GPs in 151 consecutive children referred for migraines to our out-patient neuropaediatric department [8]. In this study, ibuprofen was prescribed to only $30.3 \%$ of the children and only $15.2 \%$ of the children were both prescribed an appropriate dose of ibuprofen and told to take it early in the course of the attack. Another concern raised by this previous study was the fact that GPs seemed reluctant to assess the efficacy of their prescribed drug as abortive medication. In case of inefficacy, they often advised children and adolescents to take paracetamol more frequently, and in last resort, every day [8]. This is in accordance with the present finding that $54 \%$ of GPs did not limit number of doses taken during the same attack.

\section{Medication overuse}

Excessive symptomatic medication may conduct to medication overuse (MO) which has been proposed as a risk factor for migraine transformation. The pediatric prevalence of $\mathrm{MO}$ is much variable within published hospital series $(0-82.5 \%)$ [14-23]. In a general population study, MO was seen in $0.3 \%$ of $12-14$ years Taiwanese adolescents [24] and in $0.5 \%$ of 13-18 years Norwegians adolescents, with a higher rate for girls $(0.8 \%)$ than for boys $(0.2 \%)$ [25]. Whereas all drugs used in the acute treatment of migraine bear the risk of MO, "simple" analgesics seem wrongly considered as "harmless" by GPs [26]. This might explain the high rate of MO encountered in our daily practice. In our already mentioned previous survey, we found that only $9.1 \%$ of patients had been warned about drug abuse [8].
Another previous study, dedicated to chronic daily headache $(\mathrm{CDH})$ conducted in our department, showed that analgesic abuse was present in $52.9 \%$ of them [27]. At the time when this paper was published, this MO rate ranked third within published series of $\mathrm{CDH}$ in children and adolescents. The two published series which had a greater percentage of analgesic abuse were those of Esposito et al. [20] and Vasconcellos et al. [22], where MO rate amounted to respectively, 82.5 and $65 \%$.

\section{Reasons for ibuprofen under prescription}

One of the reasons that may impede ibuprofen as first intention choice abortive drug is the fear about adverse events. Ibuprofen is the non-steroidal anti-inflammatory drug most prescribed for the treatment of fever and moderate pain in childhood. At a dosage of $4-10 \mathrm{mg} / \mathrm{kg}$, it is as effective a pediatric analgesic as acetaminophen, $7-15 \mathrm{mg} / \mathrm{kg}$, whereas at a dosage of $5-10 \mathrm{mg} / \mathrm{kg}$, especially a $10 \mathrm{mg} / \mathrm{kg}$ dosage, it is a more efficacious pediatric antipyretic than acetaminophen, $10-15 \mathrm{mg} / \mathrm{kg}$ [28]. However, concern was raised as lot of studies (case reports, cohort studies, case-control studies and one multicenter double-blind randomized control trial) had reported ibuprofen adverse effects at therapeutics doses. They documented an increased risk of invasive group A streptococcal infection after chickenpox and of acute renal failure in case of hypovolemia after a treatment by ibuprofen. In the largest randomized-controlled clinical trial ever conducted to assess the safety of antipyretic use in 2-year-old [29], the data indicated that incidence rates for serious adverse clinical events requiring hospitalization among febrile children treated with acetaminophen or ibuprofen were low and did not vary significantly with choice of antipyretic. The meta-analysis by Perrott et al. [28] also concluded that the data available so far did not provide any evidence that both drugs differed in safety from each other or from placebo. Nevertheless, as a precaution, ibuprofen was not recommended for the treatment of fever or moderate pain during chickenpox or during a disease with a risk of dehydration, until other pharmacoepidemiological studies more accurately quantified the risk of adverse events of ibuprofen in children. As a consequence, fearing of GPs appears excessive as most of pediatric migraine attacks may not occur during chickenpox or during a disease with a risk of dehydration.

\section{Preventive therapy}

There is currently no consensus about when to initiate preventive measures, but daily preventive therapy is warranted in about $20-30 \%$ of young migraineurs [30]. Most 
authors consider three to four migraines per month as the threshold for considering the preventive treatment in pediatric patients. Besides headache frequency, the decision to initiate preventive therapy must also take into account the disability caused by the headache disorder. Headache diaries are extremely valuable for an accurate determination of frequency, severity, and disability and provide a basis for decisions about preventive therapy [31]. Uncommon migraine conditions such as basilar or hemiplegic migraines [32], patients who are unable to tolerate, overuse, or have contraindications for acute therapies should also be considered for prophylactic therapy [32]. Patient preference in addition to financial issues may warrant therapy as well [32].

We can only speculate why $52 \%$ of GPs deliberately refused to initiate preventive therapy. In a community sample of adolescents, nearly one third of adolescent migraineurs met criteria for preventive therapy, whereas only 19\% received it [33]. The Céleste study was a 6-month prospective multicenter study conducted in France which included 486 children and adolescents with primary headache, whose aim was to assess clinical features and therapeutic management throughout France [34]. In the Céleste study, around $10 \%$ of children were prescribed a preventive therapy by GPs (submitted). Moreover GPs largely favoured "old" preventive medications. Ergot alkaloids and serotonin antagonists were the two most often prescribed drugs. Newer preventive drugs, such as antiepileptic medications were rarely prescribed by GPs. The information that preventive therapy was advisable in some instances, irrespective of whether that particular child should or should not have preventive therapy initiated, was provided to $22.3 \%$ of the children diagnosed with migraine by their GPs.

Behavioral headache treatments include relaxation training, biofeedback training, cognitive-behavioral therapy, or combinations of these treatments. The availability of these therapies is limited in France. This may explain that GPs favoured pharmacologic versus non-pharmacologic preventive treatments. In the Céleste study, few patients benefited from non-pharmacologic treatments at referral. Nevertheless, following the re-evaluation by a neuropediatrician, the increase in preventive therapy concerned much more non-pharmacologic than pharmacologic measures. Whereas there was a nearly twofold increase in prophylactic treatment prescription, there was a fivefold and a 23-fold increase for both psychotherapy and relaxation training, respectively. Biofeedback prescription increased from 0 to 8 patients between prereferral and referral. These findings may also indicate that besides limited availability, there may also be a lack of knowledge of the possibility of these therapeutic options by GPs.

\section{Referral}

Studies investigating the utility of referring patients with headache to a specialist are important for several reasons, including planning for optimal care for headache patients to a reasonable cost for the society. The referral decision is a complex process involving aspects related to patient's factors, clinical factors, consultant factors and time available for the consultation [35]. In an adult study, variables such as pain intensity, number of migraine symptoms, attack duration and disability were associated with increased frequency of consultation [36]. Such studies on reasons for specialist referral regarding headache are relatively sparse in children, despite the fact that headache represents one of the most common complaints for pediatric patients seeking health services in general practice as well as in secondary care $[37,38]$. In the already cited survey from our hospital, reasons of referral of migraine pediatric patients to our out-patient neuropaediatric department were failure to control the headaches in $37.8 \%$ of cases and as a matter of course in $37.1 \%$ [8].

Awareness and reading of HAS guidelines

Clinical practice guidelines are systematically developed statements to assist practitioner and patient decisions about appropriate health care for specific clinical circumstances. Their successful implementation should improve quality of care by decreasing inappropriate variation and expediting the application of effective advances to every day practice $[39,40]$. Despite wide promulgation, guidelines have had limited effect on changing physician behavior [41-43]. In general, little is known about the process and factors responsible for how physicians change their practice methods when they become aware of a guideline [44, 45]. Physician adherence to guidelines may be hindered by a variety of barriers, which include lack of awareness, lack of familiarity, and lack of agreement with guidelines, lack of self-efficacy, lack of outcome expectancy, the inertia of previous practice, and external barriers. Any French physician should be aware of HAS guidelines as they were distributed to every GP in France. In the study by Bianco et al. [46] dedicated to headache patient management by general practitioners in Italy, less than half $(46.7 \%)$ of the GPs modified the treatment when new scientific evidence indicated that its use for a patient was less efficacious that the new one. It seems to us that the two main factors responsible are lack of familiarity and inertia of previous practice. We could not find a correlation between knowledge of the HAS guidelines, as reflected by the GPs answering correctly to questions $1-4$, and their statement of either knowledge or 
reading of the HAS guidelines, which may stem from the small sample size.

\section{Differences between urban and rural GPs}

There were few differences between the urban and the rural GPs. The only significant difference concerned the initiation of preventive therapy. Rural GPs were more likely to initiate preventive therapy than urban GPs. Maybe this may stem from the fact that urban GPs have greater involvement in chronic disease management. In contrast, the distance which patient live from a specialist consultation did not hinder referral to a specialist. Compliance with HAS guidelines was similarly not different between urban and rural GPs.

\section{Study limitations}

Our study has several limitations. The $70 \%$ response rate may mean that the respondents were not fully representative of the population of GPs. The majority of GPs of our sample were men (95\%), whereas the general gender distribution in North of France is around $80 \%$. We have no explanation for this point. However, our analyses suggest that our respondents did not differ substantially on all other demographic and practice characteristics from the overall population of North of France GPs. Another potential methodological limitation in the way of collecting information on awareness of HAS guidelines and behavior in management of pediatric migraine patients may have implications regarding the interpretation of the results, since such data were obtained from a self-administered questionnaire by the GPs and may therefore be subject to recall bias. The possibility of a false answer by the GPs should also be considered.

\section{Conclusion}

Given the prevalence of migraine in the pediatric population, children with migraines suffer if forced to apply to specialist centers for proper treatment. GPs must become more involved in the management of pediatric migraine. Thus GPs should rely on and apply the clinical guidelines for management of migraines in children. Practising guidelines takes time to incorporate best external evidence with clinical expertise, GPs need to learn how to use tools that allow them to find, critically appraise and apply the evidence to their pediatric patients. Interventions to improve adherence should also endeavor to identify and overcome barriers that hinder adherence to the implementation of recommendations by GPs.
Conflict of interest None.

\section{References}

1. Abu-Arefah I, Russell G (1994) Prevalence of headache and migraine in schoolchildren. Br Med J 309:765-769

2. Stewart WF, Linet MS, Celentano DD, Van Natta M, Ziegler D (1991) Age- and sex-specific incidence rates of migraine with and without visual aura. Am J Epidemiol 134:1111-1120

3. Split W, Neuman W (1999) Epidemiology of migraine among students from randomly selected secondary schools in Lodz. Headache 39:494-501

4. Stang PE, Osterhaus JT (1993) Impact of migraine in the United States: data from the national health interview survey. Headache 33:29-35

5. Powers SW, Patton SR, Hommel KA, Hershey AD (2003) Quality of life in childhood migraines: clinical impact and comparison to other chronic illnesses. Pediatrics 112(1 Pt 1):e1-e5

6. Annequin D, Tourniaire B, Dumas C (2000) La migraine, pathologie méconnue chez l'enfant [Migraine, misunderstood pathology in children]. Arch Pediatr 7:985-990

7. Agence Nationale d'Accréditation et d'Evaluation en Santé (ANAES) (2003) Recommandations pour la pratique clinique. Prise en charge diagnostique et thérapeutique de la migraine chez l'adulte et l'enfant. Rev Neurol 159:126-135

8. Cuvellier JC, Fily A, Joriot S, Cuisset JM, Vallée L (2007) French general practitioners' management of children's migraine headaches. Headache 47:1282-1292

9. Damen L, Bruijn JK, Verhagen AP, Berger MY, Passchier J, Koes BW (2005) Symptomatic treatment of migraine in children: a systematic review of medication trials. Pediatrics 116:e295e302

10. Lewis D, Ashwal S, Hershey A, Hirtz D, Yonker M, Silberstein S, American Academy of Neurology Quality Standards Subcommittee; Practice Committee of the Child Neurology Society (2004) Practice parameter: pharmacological treatment of migraine headache in children and adolescents: report of the American Academy of Neurology Quality Standards Subcommittee and the Practice Committee of the Child Neurology Society. Neurology 63:2215-2224

11. Hämäläinen ML, Hoppu K, Valkeila E, Santavuori P (1997) Ibuprofen or acetaminophen for the acute treatment of migraine in children: a double-blind, randomized, placebo-controlled, crossover study. Neurology 48:103-107

12. Lewis DW (2002) Children's ibuprofen suspension for the acute treatment of pediatric migraine. Headache 42:780-786

13. Evers S, Rahmann A, Kraemer C, Kurlemann G, Debus O, Husstedt IW, Frese A (2006) Treatment of childhood migraine attacks with oral zolmitriptan and ibuprofen. Neurology 67:497-499

14. Moore AJ, Shevell M (2004) Chronic daily headaches in pediatric neurology practice. J Child Neurol 19:925-929

15. Seshia SS (2004) Chronic daily headache in children and adolescents. Can J Neurol Sci 31:319-323

16. Hershey AD, Powers SW, Bentti AL, LeCates S, deGrauw TJ (2001) Characterization of chronic daily headaches in children in a multidisciplinary headache center. Neurology 56:1032-1037

17. Galli F, Patron L, Russo PM, Bruni O, Ferini-Strambi L, Guidetti V (2004) Chronic daily headache in childhood and adolescence: clinical aspects and a 4-year follow-up. Cephalalgia 24:850-858

18. Abu-Arafeh I (2001) Chronic tension-type headache in children and adolescents. Cephalalgia 21:830-836

19. Chakravarty A (2005) Chronic daily headache in children and adolescents: a clinic based study from India. Cephalalgia 25:795800 
20. Esposito SB, Gherpelli JL (2004) Chronic daily headaches in children and adolescents: a study of clinical characteristics. Cephalalgia 24:476-482

21. Koenig MA, Gladstein J, McCarter RJ, Hershey AD, Wasiewski W; Pediatric Committee of the American Headache Society (2002) Pediatric Committee of the American Headache Society. Chronic daily headache in children and adolescents presenting to tertiary headache clinics. Headache 42:491-500. Erratum in: Headache 2003;43:431

22. Vasconcellos E, Pina-Garza JE, Millan EJ, Warner JS (1998) Analgesic rebound headache in children and adolescents. J Child Neurol 13:443-447

23. Pakalnis A, Butz C, Splaingard D, Kring D, Fong J (2007) Emotional problems and prevalence of medication overuse in pediatric chronic daily headache. J Child Neurol 22:1356-1359

24. Wang SJ, Fuh JL, Lu SR, Juang KD (2006) Chronic daily headache in adolescents: prevalence, impact, and medication overuse. Neurology 66:193-197

25. Dyb G, Holmen TL, Zwart JA (2006) Analgesic overuse among adolescents with headache: the Head-HUNT-Youth Study. Neurology 66:198-201

26. Hering-Hanit R, Gadoth N, Cohen A, Horev Z (2001) Successful withdrawal from analgesic abuse in a group of youngsters with chronic daily headache. J Child Neurol 16:448-449

27. Cuvellier JC, Couttenier F, Joriot-Chekaf S, Vallée L (2008) Chronic daily headache in French children and adolescents. Pediatr Neurol 38:93-98

28. Perrott DA, Piira T, Goodenough B, Champion GD (2004) Efficacy and safety of acetaminophen vs. ibuprofen for treating children's pain or fever: a meta-analysis. Arch Pediatr Adolesc Med 158:521-526

29. Lesko SM, Mitchell AA (1999) The safety of acetaminophen and ibuprofen among children younger than two years old. Pediatrics 104:e39

30. Lewis DW, Diamond S, Scott D, Jones V (2004) Prophylactic treatment of pediatric migraine. Headache 44:230-237

31. Hämäläinen ML (2006) Migraine in children and adolescents: a guide to drug treatment. CNS Drugs 20:813-820

32. Silberstein SD (2000) Practice parameter: evidence-based guidelines for migraine headache (an evidence-based review): report of the Quality Standards Subcommittee of the American Academy of Neurology. Neurology 55:754-762. Erratum in: Neurology 2000;56:142
33. Winner P, Diamond M, Freitag F, Reed ML, Bigal M, Lipton RB (2006) Migraine prevalence, disability and prevention need in a community sample of adolescents: results from the American Migraine Prevalence and Prevention (AMPP) Study. Headache 46:834

34. Cuvellier JC, Donnet A, Guégan-Massardier E, Nachit-Ouinekh F, Parain D, Vallée L (2008) Clinical features of primary headache in children: a multicentre hospital-based study in France. Cephalalgia 28:1145-1153

35. Evans A (1993) A study of the referral decision in general practice. Fam Pract 10:104-110

36. Lipton RB, Stewart WF, Simon D (1998) Medial consultation for migraine: results from the American Migraine Study. Headache 38:87-96

37. Cockerell OC, Goodridge DMG, Brodie D, Sander JWAS, Shorvon SD (2001) Neurological disease in a defined population: the results of a pilot study in two general practices. Neuroepidemiology 15:73-82

38. Patterson VH, Esmonde TFG (1993) Comparison of the handling of neurological outpatient referrals by general physicians. J Neurol Neurosurg Psychiatry 56:830

39. Field MJ, Lohr MJ (1990) Clinical practice guidelines: directions for a new program. National Academy Press, Washington DC

40. Audet AM, Greenfield S, Field M (1990) Medical practice guidelines: current activities and future directions. Ann Intern Med 30:709-714

41. Chassin MR (1990) Practice guidelines: best hope for quality improvement in the 1990s. J Occup Med 32:1199-1206

42. Lomas J, Anderson GM, Domnick-Pierre K, Vayda E, Enkin MW, Hannah WJ (1989) Do practice guidelines guide practice? The effect of a consensus statement on the practice of physicians. N Engl J Med 321:1306-1311

43. Woolf SH (1993) Practice guidelines: a new reality in medicine, III: impact on patient care. Arch Intern Med 153:2646-2655

44. Greco PJ, Eisenberg JM (1993) Changing physicians' practices. N Engl J Med 329:1271-1274

45. Goldman L (1990) Changing physicians' behavior: the pot and the kettle. N Engl J Med 322:1524-1525

46. Bianco A, Parente MM, De Caro E, Iannacchero R, Cannistrà U, Angelillo IF (2005) Evidence-based medicine and headache patient management by general practitioners in Italy. Cephalalgia 25:767-775 